\title{
MARTÍN GELABERT Y LA PRINCEPS DEL QUIJOTE: LA EDICIÓN BARCELONESA DE 1704
}

La rica tradición bibliográfica sobre las ediciones antiguas del Quijote ha destacado siempre el fugaz destino de la princeps (Madrid, Juan de la Cuesta, 1605): apenas seis meses después de la publicación ' su estrella decae rápidamente, y la segunda edición madrileña viene a arrebatarle las galas de la posteridad textual.

' La tasa de la princeps, último requisito legal para sacar un libro a la venta, está fechada a 20 de diciembre de 1604. La obra tuvo que salir a la luz en los primeros días de enero de 1605 . La segunda edición repite los preliminares de la primera e incorpora el privilegio para el reino de Portugal, con fecha de 9 de febrero de 1605; no es probable que Francisco de Robles, el librero que coste6 ambas ediciones, dispusiera de nuevos ejemplares antes de fines de abril o primeros de mayo. C. PÉRez PASTOR (Documentos cervantinos hasta ahora inéditos, vol. I, Madrid, 1897, pp. 285-295, y vol. II, Madrid, 1902, pp. 561-568) dio a conocer un asiento del Libro de la Hermandad de Impresores de Madrid en que se registra la entrada de dos ejemplares del Quijote. Tras una vacilación inicial, acabó fechando el documento en 15 de mayo de 1605. Puesto que las prensas tenían la obligación de enviar a la Hermandad ejemplares de los libros en cuanto los terminaban, parece lógico suponer que el asiento se refiere a dos volúmenes de la segunda tirada, que a la sazón acababa de imprimirse. Pérez Pastor (op. cit., vol. I, pp. 141-144) y F. RoDRIGUEZ MARIN (Nuevos documentos cervantinos. Madrid, 1914, pp. 282-283) exhumaron el poder notarial de Cervantes a Robles para «ymprimir e vender su Quijote en Portugal y Aragón, fechado en 12 de abril de 1605. Las urgencias de Robles por ampliar el privilegio original a todos los reinos de España - con lo que podría impedir nuevas iniciativas tan perjudiciales para sus intereses como las dos rápidas ediciones de Lisboa- aceleraron el curso de la impresión, hasta el punto de que una serie de pliegos se estampó fuera de la prensa Madrigal-Cuesta. Un resumen detallado de estas prisas editoriales puede consultarse en el artículo de R. M. Flores *The Printers of the Second Madrid Edition of Don Quixote, Part I, and the Consequences of the Division of Labour*, Bulletin of Hispanic Studies, XLVIII, 1971, pp. 195-196. 
La princeps se sume en un silencio de casi doscientos años, en los que es olvidada por completo y pierde toda individualidad, hasta el extremo de que las dos ediciones de 1605 llegan a confundirse en una sola ${ }^{2}$. En 1897, Leopoldo Rius, al referirse a la historia del texto de la obra, realizaba por vez primera una afirmación que ha ido transmitiéndose de repertorio en repertorio y se ha tenido por indiscutible: «Exceptuando las dos ediciones de Lisboa, todas las que se han impreso durante más de 250 años siguen el texto de la segunda, la cual ipso facto era tenida por primera; lo que demuestra el hecho, difícil de explicar, de haber en seguida desaparecido los pocos ejemplares que de la edición príncipe se tiraron" ${ }^{3}$.

Para dar cuenta de un silencio tan hondo como repentino, de ese «hecho difícil de explicar", la erudición de los últimos cien años ha intentado respuestas diversas, basadas las más de las veces en una improbable intervención del librero o - lo que aún resulta menos verosímil- del mismo Cervantes ${ }^{4}, y$ ha indagado

\footnotetext{
${ }^{2}$ La segunda edición de Juan de la Cuesta sirvió de modelo a la primera valenciana (Pedro Patricio Mey, 1605), la bruselense de Roger Velpius (1607) y la tercera edición de Cuesta (1608); a su vez, uno de los dos textos valencianos fue utilizado por Juan Bautista Bidello en Milán (1611) y se recuperó todavía para el texto de la Primera parte en la edición completa de Barcelona (1617). Hasta fines del siglo xviI se pensaba que Juan de la Cuesta habia impreso en 1605 una sola edición del Quijote. Fue John Bowle, en una carta dirigida a Thomas Percy, quien advirtió la existencia de dos tiradas distintas: A Letter to the Reverend Dr. Percy, Concerning a New and Classical Edition of Historia del Valeroso Cavallero 'Don Quixote de la Mancha'. Londres, 1777. Dada su extensión («fifty-six pages of text ), D. EISENBERG no reproduce la carta en su edición de la correspondencia cervantina entre ambos ilustrados (Percy-Bowle. Cervantine Correspondence. Exeter, 1987), aunque la clasifica con el núm. 36 y la glosa brevemente (p. 43). Para un análisis del proceso que llevó a determinar la precedencia correcta de las dos ediciones, en el que intervinieron sucesivamente Martín Fernández de Navarrete, Vicente Salvá, Gustave Brunet y Juan Eugenio Hartzenbusch, véase sólo H. Serts, La colección cervantina de la Sociedad Hispánica de América. Urbana, 1918, pp. 17-20.

${ }^{3}$ L. RuUs, Bibliografia critica de las obras de Miguel de Cervantes Saavedra. Madrid, 1895, vol. I, p. 2 (hay edición facsimilar: Nueva York, 1970). R. Flores -aunque escudado tras un prudente apparently - insiste en que awith the exception of the second Madrid edition and the two Lisbon editions, apparently no other edition has been based on the editio princeps alone* ( $₫$ The Printers of the Second Madrid Edition of Don Quixotew, cit., p. 194, nota 1.

4 *Es de presumir que el mismo Cervantes, o el librero, procurarian retirar, en cuanto cabia, los ejemplares, activando solamente la venta de la segunda impresión de Madrid, que es la completa, y esto explicaria el hecho de haber servido esta última de original a todas las posteriores», L. RiUs, op. cit., vol. I, p. 4. J. SuNE, en su Bibliografia critica de ediciones del Quijote impresas desde 1605 hasta 1917. Barcelona, 1917, p. 5, se limita a reproducir las palabras de Rius.
} 
en los archivos en busca de noticias acerca de la historia de los volúmenes $^{5}$. Como quiera que fuese, los avatares de la primera edición no han dejado de suscitar interés hasta el presente. Esta nota, centrada en el estudio de la segunda impresión realizada en Barcelona (Martín Gelabert, 1704), no persigue otro objetivo que matizar ciertas imprecisiones que se han colado en los repertorios bibliográficos, al tiempo que ofrece nuevos datos sobre la genealogía textual de la princeps del Quijote.

\section{Descripción de la portada:}

VIDA, / Y HECHOS / DEL / INGENIOSO CAVALLERO / DON QVIXOTE / DE LA MANCHA. / COMPVESTA / Por Miguel de Cervantes Saavedra. / TOMO I. Y IJ. / Pliegos )( [una cruz] )( 88. y med. / CON LICENCIA: / [filete negro] / Barcel. En la Imprenta administrada por Martin Gelabert, / delante la Retoria de N. S. del Pino, / Año $1704^{6}$.

5 Gracias a las pesquisas de F. Rodrfguez Marin en el Archivo de Indias, sabemos que 84 ejemplares del Quijote fueron embarcados en la flota de Tierra Firme, con destino a Perú, entre el 25 de febrero y el 11 de abril de 1605. Es probable que todos esos volúmenes pertenecieran a la primera edición. En los meses de junio y julio se cargan 262 nuevos tomos en los navios de la flota destinada a Nueva España; conocemos incluso los nombres de las embarcaciones en que se instalaron las cajas. Así, Rodriguez Marin entiende que los ejemplares de la princeps no dejaron de circular porque fueran retirados de la venta, sino porque se fletaron hacia América: «Probablemente, en entrambas flotas se remitió a las Indias casi toda la edición príncipe del Quijotew, que cifra en poco más de 700 ejemplares (El Quijote y don Quijote en América. Madrid, 1911, p. 39; para los datos aducidos, pp. 33-35). J. SUNE (op. cit., pp. 5-6) acepta que los cinco ejemplares registrados el 25 de febrero correspondían a la princeps, pero no se muestra tan seguro en lo que toca a los demás, «puesto que ya por aquellos meses andaban de molde las ediciones de Lisboa y la segunda impresa por el mismo Juan de la Cuesta .

- He consultado personalmente tres ejemplares: los dos conservados en la Biblioteca Nacional de Madrid (Cervantes 2591 y R. 32185) y el que custodia la Biblioteca de Cataluna (Cerv 7-III-3); la descripción se corresponde con la portada de los dos primeros. En el ejemplar barcelonés, perteneciente a la colección Bonsoms, el texto no alterna tinta roja y negra, sino que va solamente en negro y añade al fin el nombre del librero: *A costa de Raymundo Bons, Mercader de libros: / vendense en su Casa.. Lo describe J. Givankl en el Catálogo de la Colección Cervantina. Barcelona, 1941, vol. I, pp. 192-193, núm. 151; hay una excelente reproducción de esta portada en Iconografía de las ediciones del Quijote. Barcelona, 1905, vol. I, p. 29. A lo que se me alcanza, no hay otras diferencias, externas o internas, entre los ejemplares citados. H. SERis (op. cit., p. 71, núm. 27) registra una portada algo distinta: «Este ejemplar difiere del descrito por Rius en lo siguiente: $10^{\circ}$ la portada está impresa en rojo y negro; $2 .^{\circ}$ pone TOMO I en vez de TOMO I. y II; $3 .^{\circ}$ no lleva el nombre del editor, y $4 .^{\circ}$ tiene segunda portada antes de la p. 339, igual a la primera a excepción de estar impresa en negro y decir: TOMO II / Pliegos 45 . . En resumen, cabe hablar de 
Es una edición en $8^{\circ}$ que reúne las dos partes de la obra en un volumen. Tiene 6 folios preliminares, 690 páginas a doble columna y 3 folios sin paginar con la tabla de capítulos, también a dos columnas. Cada columna tiene 41 renglones. La impresión y el papel son de mediana calidad. Sobre la filiación del texto se ha acatado el juicio de Rius: "se tomó de la edición de Bruselas de 1662, llamándose aquí partes lo que allá libros; pero a toda la parte segunda se la titula en esta edición Quinta parte; y como viene impresa en inmediata continuidad a las anteriores, sin portada, dedicatoria, prólogo ni preliminar alguno, desaparece la división y separación que entre ambas partes de la obra su autor estableción" ?.

No le falta su punto de razón al ilustre bibliógrafo; y es que, en efecto, un examen de las características externas del libro, que atienda únicamente a la disposición de los preliminares y a la distribución de las partes, induce a relacionarlo con la bella edición que Juan Mommarte imprimió en Bruselas en $1662^{8}$ : en

tres variedades distintas de una misma edición: (1) una portada a dos tintas, con sólo el nombre del impresor, (2) una portada a dos tintas, idéntica a la anterior, para cada parte del libro, y (3) una portada a una tinta, que incluye el nombre del librero. Hay que suponer que las dos primeras emisiones se vendian directamente en la imprenta administrada por Gelabert, y que parte de la edición, con una portada menos lujosa, fue costeada por el librero Raimundo Bons. El añadido de una portada tras la pág. 338 sirve para marcar un hiato entre la Primera parte y la Segunda, que carece de preliminares. Podría pensarse incluso que responde a la voluntad de partir la obra en dos volúmenes, extremo que parece atestiguar el ejemplar de la Bibliothèque Nationale de París, el cual, según Grvanel, ibid., solamente consta del primer tomo. Con todo, la Segunda parte no inicia pliego independiente, sino que comienza en $\mathrm{Y} 2 \mathrm{r}$, lo que dificulta que pudiera desgajarse de la primera. Utilizo el término emisión con la acepción que le da J. Moll en «Problemas bibliográficos del libro del Siglo de Oro», Boletín de la Real Academia Española, LIX, 1979, pp. 59-60.

${ }^{7}$ L Rius (op. cit., p. 29, núm. 28). J. GIVANEL, con mejor tino, considera la posibilidad de que el modelo directo no sea Bruselas 1662, sino alguna de las impresiones derivadas de ésta: «sigue, a nuestro parecer, alguna de las que tienen la segunda parte en cuatro libros y llevan la citada aprobación valenciana, y estas dos cosas las hemos visto en las de Bruselas, 1662 y 1671, y Amberes, 1673 y 1697. (op. cit., vol. I, pp. 192-193, núm. 151). Salvo el artículo de F. Rico citado en la nota 12 , no conozco ningún estudio reciente que mencione la edición de 1704. El artículo de E. RodrfGuez-CEPEDA "Los Quijotes del siglo XVIII. 1: La imprenta de Manuel Martín», Cervantes, 8:1, 1988, pp. 61-108, describe y analiza únicamente impresiones posteriores a 1750; F. AgUILAR PINAL, "Cervantes en el siglo XVIII, Anales Cervantinos, XXI, 1983, pp. 153-163, recuerda tan sólo, a propósito de la edición de 1704, el hiato de treinta años que la separa de la última realizada en España durante el siglo xVII (Madrid, 1674).

ss una de las primeras ediciones ilustradas, con dos frontispicios y 14 láminas grabados en cobre por F. Boutats y tomados de la edición holandesa de la obra, impresa en Dordrecht en 1657. Las estampas se repetirán en ediciones sucesivas (vid. GIVANEL, op. cit., pp. 147-148, núm. 101). 
primer lugar, el título es el mismo ${ }^{9}$. Segundo, se reproduce la aprobación de la primera edición de Pedro Patricio Mey, dada por Fray Luis Pellicer en el Jesús de Valencia, a 18 de julio de 1605; esa aprobación reaparece en la segunda edición valenciana de 1605, en la edición barcelonesa de 1617 y en la bruselense de 1662, así como en todos los descendientes de ésta (Bruselas, Pedro de la Calle, 1671; Amberes, Jerónimo y Juan Bautista Verdussen, 1673; Amberes, Henrico y Cornelio Verdussen, 1697). Tercero, el orden de los versos preliminares incluye el trastrueque originado en la edición de $1662^{10}$. Por último, también proviene de esta rama la ordenación de la obra en ocho libros, para ajus-

9 Vida y obras aparece por vez primera en la edición de Mommarte, y por ese nombre se conocerá al Quijote durante más de un siglo, hasta que en 1780 la Academia restituya el original El ingenioso hidalgo don Quijote de la Mancha. $\mathrm{Ni}$ siquiera en las traducciones se asienta un título de forma tan duradera. Las versiones inglesas de 1612,1619-1620, 1652 y 1675 presentan The History of the Valorous and Witty Knight Errant, Don Quixote de la Mancha, pero en 1687 encontramos The History of the Most Renowned Don Quixote of Mancha and his Trust Squire Sancho Pancha, y en 1689 The Delightful Hystory of Don Quixot. El rótulo The Life and Exploits of the Ingenious Gentleman Don Quixote de la Mancha (1742) llegará a Inglaterra solamente cuando Charles Jarvis traduzca la edición de Tonson, quien la titulo, siguiendo la tradición castellana, Vida y hechos. Por lo que respecta a Francia, la variedad es igualmente notable: L'ingénieux don Quixote de la Manche (1614), Le valeureux don Quixote, ou l'histoire de ses grands exploicts d'armes, fidèles amours \& adventures estranges (1616). Seconde partie de l'histoire de l'ingénieux et redoutable chevalier, don Quichot de la Manche (1618). A partir de la edición parisiense de Claude Barbin (1678) se impone Histoire de l'admirable Don Quixotte de la Manche, y ése será su título hasta fines del siglo xvir. En 1799 se queda en un mondo Don Quichotte de la Manche, aunque admirable reaparecerá en algunas ediciones del XIX, en competencia con ed incomparable de París 1832. L'ingénieux chevalier está en la edición parisina de 1821. En italiano, la solución L'ingegnoso cittadino don Chisciotte della Mancia (Venecia, 1622) resulta un éxito, y se establece hasta que la edición veneciana de 1755 pasa a titular la obra Vita e azioni dell'ingegnoso cittadino don Chisciotte della Mancia. La edición milanesa de 1840 ofrece, por fin, las aventuras de L'ingegnoso idalgo Don Chisciotte della Mancia.

${ }_{10}$ En la princeps, los poemas laudatorios llevan el orden siguiente: los versos de cabo roto de Urganda la desconocida, el soneto de Amadís, el de don Belianís de Grecia, el de Oriana, el de Gandalín, las dos composiciones del Donoso, el soneto de Orlando, el del caballero del Febo, el de Solisdán y el diálogo entre Babieca y Rocinante. Frente a la disposición original, la edición de $1662-y$, a su zaga, la de Martín Gelabert- coloca el soneto de Orlando en lugar del de Oriana, y sitúa éste entre el del caballero del Febo y el de Solisdán. Por otra parte, en las ediciones bruselenses de Huberto Antonio (1611 y 1617) falta el soneto de Solisdán. Los once poemas desaparecen en la edición madrileña de Francisco Martínez (1637) y en toda la rama textual derivada: Madrid, Imprenta Real, 1647; Madrid, Melchor Sánchez, 1655; Madrid, Mateo Fernández, 1662; Imprenta Real, 1668; Madrid, Andrés García de la Iglesia y Roque Rico de Miranda, 1674. 
tar la simetría de la Primera parte a la Segunda ". Frente a su modelo, Barcelona prefiere el nombre de partes al de libros, distingue ocho partes tan sólo en la tabla de capítulos y en el cuerpo de la obra llama Quinta parte a todo el texto de 1615.

Visto el cañamazo en que se estructuran los distintos materiales, resulta comprensible que los repertorios bibliográficos hayan adscrito la edición barcelonesa a la tradición de Bruselas 1662. Sin duda alguna sigue un texto de esa familia en la ordenación, disposición y clasificación de las partes de la obra y los preliminares. Con todo, es de lamentar que nadie se haya detenido a cotejar algunos renglones del texto. Cierto que la regular monotonía con que unas ediciones copian de otras invita a suponer que Martín Gelabert pudo haberse valido de un ejemplar de la rama de Juan Mommarte. Pero basta pasear la vista por la primera página del capítulo I para dar con una lectura intrigante. El fragmento es de sobras conocido, pero no estará de más reproducirlo:

Quieren dezir que tenía el sobrenombre de Quixada, o Quesada, que en esto ay alguna diferencia en los autores que deste caso escriven, aunque por conjeturas verosímiles se dexa entender que se llamava Quexana

Cualquiera que esté familiarizado con el texto crítico de la obra recordará la lección Quexana, presente tan sólo en la princeps ${ }^{12}$ y en los dos textos de Lisboa de 1605 . La segunda edición madrileña, y a su zaga el resto de testimonios de los siglos xviI y XVIII, enmienda esa lectura anómala en el correcto Quixana. El caso es que Quexana reaparece en el texto de Barcelona 1704. Aunque pudiera tratarse de un simple azar, la coincidencia en el error basta para despertar sospechas y animar a la comprobación de otros loci critici. No hace falta buscar demasiado: los dos célebres y discutidos pasajes de la pérdida y restitución del asno (caps. XXIII y XXX), incorporados al texto a partir de la segunda edición madrileña, también faltan en Barcelona 1704. La posibilidad insinuada por Quexana se convierte ahora en una cer-

"Libro quinto, capitulos 1-16; Libro sexto, capitulos 17-32; Libro séptimo, capítulos 33-52; Libro octavo, capítulos 53-74.

${ }^{12} \mathrm{Y}$ no en todos los ejemplares, sino sólo en los pertenecientes al family group A, pues en la reimpresión del pliego A se enmendó por la forma Quixana, como ha demostrado R. Flores en The Compositors of the First and Second Madrid Editions of Don Quixote Part 1. Londres, 1975, p. 21, variante núm. 5. Sobre Quexana y alguna otra vacilación del primer capítulo, véase ahora F. Rico, ¿Quexana», Evphrosyne, XXII, 1994, pp. 431-439. 
teza razonable: la Primera parte del Quijote de Gelabert copia un ejemplar de la primera edición de Cuesta.

Un cotejo exhaustivo de los lugares críticos de los distintos testimonios demuestra a las claras que los tipógrafos utilizaron por copión el texto de la princeps. En el Apéndice I se reproduce un sumario de los resultados obtenidos: se ha seleccionado una variante significativa (lectura aislada de la primera edición de Cuesta frente a la tradición impresa posterior, representada por la seminal segunda edición madrileña) de cada uno de los capítulos de la Primera parte. En los cincuenta y un ejemplos aducidos (no hay variantes útiles en el cap. XXXIX), Barcelona 1704 lee con la princeps: son lecturas coincidentes frente al resto de la tradición impresa. El resultado no admite duda alguna, pues recoge numerosos errores comunes que el texto de Barcelona no podía cometer sin tener delante un modelo - la princeps - con esos mismos errores ${ }^{13}$. Junto a los ya mencionados ejemplos del robo y la recuperación del rucio pueden destacarse, por sobradamente conocidos, la falta del epígrafe del capítulo XLIII y la presencia de diversos pasajes que fueron suprimidos desde la segunda edición de Cuesta (caps. XIX y XXVI, así como la - a juicio del censor- poco reverente mención del rosario que se fabricó Don Quijote durante su penitencia en Sierra Morena).

Una vez establecida la fuente textual de la Primera parte del Quijote de 1704, cabe preguntarse por el grado de fidelidad al modelo. El Apéndice II pone de relieve un apego más que notable al texto de copia ${ }^{14}$. Las diferencias pueden achacarse casi siempre a errores mecánicos, simples equivocaciones de cajista, y no se advierte voluntad alguna de cambiar o retocar el texto que se lee, sino más bien un notable afán por ceñirse estrecha-

${ }^{13}$ Cabria la posibilidad de que el modelo fuera una de las ediciones portuguesas de 1605, las cuales, como queda dicho, copiaron de la princeps, incluyen la lección Quexana y carecen asimismo de los fragmentos sobre el rucio. He cotejado las dos ediciones con el texto de Barcelona, y puede desecharse toda relación. Valga un solo ejemplo: cuando Frey Antonio Freyre, el responsable de la aprobación de ambas ediciones, suprimió algunos pasajes de la princeps, los cajistas portugueses suturaron los tajos abiertos por la censura con no poca habilidad, de modo que las lagunas resultan imperceptibles. Todos los pasajes estragados por Freyre aparecen intactos en Barcelona 1704. J. SUNÉ (op. cit., pp. 13-14) ofrece una lista con las principales variantes de las ediciones de Juan Rodriguez y Pedro Crasbeeck que también he comprobado, con idénticos resultados.

${ }^{14}$ Apego que lleva a mantener erratas tan flagrantes como las registradas en los capítulos XXXIII y XLVII, y aun otras no recogidas en el apéndice: asi. atrevientos por atrevimientos (cap. X, fol. 35v., lín. 10), corregida ya en las ediciones de Lisboa. 
mente a él ${ }^{15}$. El texto resulta conservador incluso en los cambios ortográficos, cifrados en una tímida adecuación a la norma de principios del xvIII: se sustituye la $u$ consonántica por $v$ (cavallero) y se vacila en el uso de la $h$ (escribe arrieros frente al harrieros de la primera edición, pero mantiene la grafía orizonte). La puntuación es prácticamente idéntica, con la misma distribución de comas, puntos y sobre todo dos puntos y paréntesis; la conjunción pues aparece entre comas, y una coma precede a la conjunción $y$ en los períodos enumerativos; se tiende a acentuar las palabras agudas acabadas en vocal y se utiliza el diacrítico para la preposición à Así, pues, el componedor «set what he read, or what he thought he had read, regardless of whether or not it made sensen ${ }^{16}$.

Para determinar el modelo de la Segunda parte se ha confrontado el capítulo XX de la princeps (Juan de la Cuesta, 1615) con la edición de Gelabert y los cuatro testimonios fundamentales en la transmisión textual: Valencia 1616, Barcelona 1617, Madrid 1637 y Bruselas 1662 (Apéndice III). La selección ha resultado suficiente, pues el cotejo demuestra (núms. 3, 7, 10, 14, 17, $19,21,24,25,26,29,33,34,41,45$ y 46) que la Segunda parte toma el texto de la primera edición barcelonesa, estampada en $1617^{17}$. De nuevo las variantes aisladas de 1704 (núms. 5, 6, 15, $30,32,38,42,50$ y 52 ) son erratas y errores mecánicos, nunca enmiendas. El principio de fidelidad se mantuvo también aquí, y lleva asimismo a preservar erratas del modelo, como en la variante núm. 14. Todo parece indicar que ningún corrector revisó las pruebas.

Ha sido posible, incluso, dar con la fuente exacta de los preliminares. Queda claro que sólo puede tratarse de la edición de Bruselas 1662 o de alguna de las tres que dependen textualmente de ella: Bruselas 1671, Amberes 1673 y Amberes 1697. Aunque los poemas laudatorios no ofrecen variantes que permitan detectar errores comunes conjuntivos, el Prólogo al lector reco-

is Nótese el caso de la variante 8, en que cae pocos y no se modifica el texto, aunque el resultado carezca de sentido. Las variantes 12 y 14 también pueden achacarse a errores mecánicos: la primera es un caso de duplografía, y la segunda un homoioteleuton por atracción de las formas su... su.

16 Como señala R. M. Flores, a propósito de otras cuestiones, en The Compositors, op. cit., p. 81 .

17 Del cotejo se deduce, además, que la edición barcelonesa tiene por modelo a la valenciana (núms. $9,12,23,26,27,28,37$ y 43) y que la rama iniciada por Bruselas 1662 se basa en el texto madrileño de 1637 o en alguno de sus descendientes (núms. 1, 2, 8, 15, 16, 35, 36, 40 y 49). 
ge, afortunadamente, tres errores comunes entre 1704 y Bruselas, Pedro de la Calle, $1671^{18}$.

¿Cuál es, en suma, la situación? ¿Podemos reconstruir los distintos momentos que conforman el proceso de elaboración del texto barcelonés? Aunque no pueda descartarse por completo la posibilidad de que el impresor buscara las ediciones más antiguas que pudiera encontrar, lo lógico es que echara mano de aquellos textos a los que tenía cómodo acceso. Por algún afortunado azar, la princeps resultó ser uno de esos textos. A falta de mejores indicios, y ateniéndome a lo dicho, se me ocurre una explicación parcial de la singularidad de la edición de 1704. Es sabido que la primera edición completa del Quijote, impresa en dos pequeños tomos en $8^{\circ}$, fue la de Barcelona 1617. Aunque la bibliografía suele adjudicarla a Bautista Sorita, lo cierto es que Rafael Vives, el librero que la costeó, repartió los trabajos de impresión entre dos talleres: confió la Primera parte a Sorita, que utilizó un ejemplar de Valencia 1605, y encargó la Segunda a Sebastián Matevat, quien siguió el texto valenciano de 1616. Una de las pocas cosas que sabemos de Martín Gelabert es que fue el administrador de la estampa Matevat por lo menos desde 1677 y que permaneció vinculado a ella hasta su muerte ${ }^{19}$. Así, el

18 Los errores son tres erratas: munda en lugar de monda (fol. Ifv., lín. 5), lo que me decis por lo que me decía (fol. I\$2v., lín. 13) y desde la que A hasta la Z por desde la $A$ que hasta la Z (fol. โ†3v., lín. 23). Son prueba de filiación más que suficiente: el cajista no pudo cometer los errores de modo independiente, sino que se deben a un texto modelo - Bruselas 1671 - que ya los contenía.

19 La falta de monografías sobre la imprenta y la librería en Barcelona durante los siglos XVII y XVIII reduce nuestro conocimiento de Gelabert a unas pocas fichas bibliográficas. Su actividad como impresor se inicia en 1660, y en 1677 figura ya como administrador de la imprenta propiedad de la familia Matevat. El Catálogo de la colección de folletos Bonsoms. Barcelona, 1959, vol. I, p. 451, ofrece una lista de 41 impresos breves realizados en el taller de Gelabert (en su mayoria sermonarios, hojas noticiosas y pliegos poéticos), a los que podemos añadir una docena de libros, entre los que destacan unas Institutiones Grammaticae de Nebrija (1692), un Kempis (1693), unas Publii Vergilii Maronis Opera (1698) y varios títulos en catalán. Una rápida ojeada a las papeletas inéditas de Isidro Bonsoms, conservadas en la Biblioteca de Cataluna, me ha permitido hallar una referencia posterior a la edición del Quijote: un pliego en $4^{\circ}$ con villancicos a San Antonio de Padua, fechado en 21 de junio de 1705. Alguna otra referencia puede verse en el Cataleg de la Biblioteca «Lambert Mata» de Ripoll. Barcelona, 1989, p. 499 (s.v. «Impremta Mathevat»), en el Catdleg de llibres $i$ fullets publicats abans de l'any 1800. Barcelona, 1990, p. 6, y en el Cataleg de la Biblioteca *Marid Vayreda* d'Olot. Barcelona, 1991, p. 533. Precisamente este último repertorio, en su núm. 502, recoge una Grammatica magna de Silvestre Casadevall con dos portadas distintas, una con el nombre del librero Jaime Balla y otra a costa de Ramon Sapera: es una distribución de la tirada análoga a la que se advierte en el Quijote. 
Quijote de Gelabert, como la Segunda parte del de 1617, resulta ser un Quijote Matevat, surgido de las mismas prensas y compuesto en el mismo taller ${ }^{20}$. Este vínculo nos sugiere una conclusión: ¿resulta descabellado suponer que el obrador de la familia Matevat conservaba todavia, a principios del siglo xviII, un ejemplar del texto impreso ochenta y siete años atrás? De ser cierto, Gelabert habría dispuesto que se copiara, y solamente habría tenido que conseguir un ejemplar para el texto de la Primera parte; por último, para elaborar los preliminares y establecer la capitulación habría recurrido a un ejemplar que estructurara ambas partes en un solo volumen, a saber, la edición bruselense de $1671^{21}$. Esta hipótesis procura un orden lógico y cronológico a la preparación de la obra - Segunda parte, Primera parte, configuración general/preliminares- que sirve para integrar una edición tan singular como es ésta de 1704, aunque no alcanza a responder el problema más importante: ¿cómo llegó a manos de Martín Gelabert, a la vuelta de un siglo, un ejemplar de la editio princeps? Es de temer que ése siga siendo uno más de entre los muchos silencios del Quijote.

\section{Gonzalo Pontón \\ Universidad Autónoma de Barcelona}

\footnotetext{
${ }^{20}$ La ubicación del taller no había cambiado desde principios del siglo xvi: en el colofón del Quijote de 1617 puede leerse «En casa de Sebastián Matevat, delante de la Retoría de Nuestra Señora del Pinox.

${ }^{21}$ La tabla de capítulos de la princeps sólo se consultó una vez, en busca de un dato muy concreto. El epígrafe del capitulo XXIX reza en ambas ediciones "Que trata de la discordia de la hermosa Dorotea...., siendo discordia una mala lectura del discreción original, restituido ya en la tabla de capitulos de la primera edición. Sin embargo, la tabla de Barcelona lee discordia, lo que prueba que se compuso a partir del texto de los epigrafes de la misma edición, ya estampada. Por otra parte, Barcelona, como la princeps, omite en el texto el epigrafe del capitulo XLIII. Al componer la tabla por el procedimiento indicado, el cajista de Barcelona advierte que en los títulos se salta del capitulo XLII al XLIV. Para solventar el problema tuvo que acudir al indice de la edición de Cuesta, de la que no sólo tomó el eprgrafe, sino también la necesaria advertencia *Comienza: Marinero soy de amory que permitía situar el pasaje. Asf, la tabla de 1704 se confeccionó a partir de los propios epigrafes, como prueba la variante discordia, pero en un caso fue necesario recurrir al indice del modelo. Sobre el célebre título del capítulo XLIII, suprimido por razones tipográficas, véase la nota de R. M. FLores «El caso del epigrafe desaparecido: capitulo 43 de la edición príncipe de la primera parte del Quijote», Nueva Revista de Filología Hispanica, XXVIII, 1980 , pp. $352-360$.
} 


\section{APÉNDICE I}

\section{LECTURAS COMUNES DE LA EDITIO PRINCEPS Y BARCELONA 1704 FRENTE AL RESTO DE LA TRADICIÓN IMPRESA}

\begin{tabular}{|c|c|c|c|}
\hline Cap. & Fol.Ain. & "Princeps" y Barcelona 1704 & Segunda Madrid y posteriores \\
\hline 1 & 1v. 12 & Quexana & Quixana \\
\hline 2 & 5r. 23 & fuguroso afincamiento & riguroso afincamiento \\
\hline 3 & 8v. 6 & Islas de Reayan & Islas de Riaran \\
\hline 4 & 12 r. 24 & la encina adonde estaba arrimada la yegua & la encina adonde estaba arrendada la yegua \\
\hline 5 & 16r. 11 & le tenia cubierto & lo tenía lleno \\
\hline 6 & 19r. $31-32$ & Florimorte de Hircania & Florismarte de Hircania \\
\hline 7 & 23 r. 31 & lo primero que hizo fue a ver sus libros & lo primero que hizo fue ir a ver sus libros \\
\hline 8 & $27 \mathrm{v}, 4$ & muy de su espacio & muy de espacio \\
\hline 9 & 31 v. 29 & al desfacer agravios & al de desfacer agravios \\
\hline 10 & 37r. 2 & Soliadisa & Sobradisa \\
\hline 11 & 38 r. 30 & que del ama, se decir & que del amor se dice \\
\hline 12 & 43v. 5 & su cayado y pellico & su ganado y pellico \\
\hline 13 & 47 r. 7 & entrado & encontrado \\
\hline 14 & 53r. 6 & El rigor del león & El rugir del león \\
\hline 15 & $62 \mathrm{v} .29$ & la peña Polio & la peña Pobre \\
\hline 16 & 67r. 22 & son tres cosas estas & son tus cosas estas \\
\hline 17 & 72v. 3 & determinándose a escuchar & deteniéndose a escuchar \\
\hline 18 & $73 v .15$ & Tellones & Follones \\
\hline 19 & $84 r .12-14$ & $\begin{array}{l}\text { Olvidábaseme de decir que advierta } \\
\text { vuestra merced que queda descomulgado] }\end{array}$ & $\begin{array}{l}\text { y dijole: Yo entiendo, Sancho, que } \\
\text { quedo descomulgado] }\end{array}$ \\
\hline 20 & 90v. 14 & que ellos eran castaños & que eran castaños \\
\hline 21 & 97v. 9 & sin saber cómo ni cómo & sin saber cómo, ni cómo no \\
\hline 22 & 101v. 18 & tres precisos de gurapas & tres precios de gurapas \\
\hline 23 & 108r. 27 & los galeotes. & los galeotes. [robo del rucio] \\
\hline 24 & $118 \mathrm{r} .26$ & de tantas buenas partes adornada & de tan buenas partes adornada \\
\hline 25 & 128r. 11 & su mujer & su mayor \\
\hline 26 & 132r. 6 & se hartó de llorar y de encomendarse a Dios & se hartó de llorar \\
\hline 27 & 139r. 2 & se aumentan en mi datio & se aúnan en mi daño \\
\hline 28 & $155 \mathrm{v} .16$ & podrá verme & podía verme \\
\hline 29 & 165v. 5 & tan solo, y $\tan \sin$ criados & tan solo, tan sin criados \\
\hline 30 & $171 \mathrm{r} .12$ & penitencia nueva. & penitencia nueva. [hallazgo del rucio] \\
\hline 31 & 172v. 21 & llegándole a ayudar & llegando a ayudar \\
\hline 32 & 181v. 26 & que algunos huéspedes que aquil la han leido & que a algunos huéspedes que aqui la han lefdo \\
\hline 33 & $183 r .21$ & le supublicaba & le suplicaba \\
\hline 34 & $198 v .22$ & los escalones que Camila baja & los escalones que Camila bajaba \\
\hline 35 & 209v. 31 & mala ventura le dé Dios & mala aventura le de Dios \\
\hline 36 & 218v. 9 & no podian hacer otra cosa & no podía hacer otra cosa \\
\hline 37 & 226v. 1 & le tuviese por loco & le tuviesen por loco \\
\hline 38 & 228r. 19 & váguidos de cabeza & váguido de cabeza \\
\hline 40 & 239 r. 26 & este mi amigo & este amigo \\
\hline 41 & $248 v .5$ & que tiene de valor este hermoso jardín & que tiene de valor en este hermoso jardín \\
\hline 42 & 258v. 3 & más llanos y más cortesanos ofrecimientos & más llenos y más cortesanos ofrecimientos \\
\hline 43 & 262 r. 4 & [Falta el epigrafe del cap. XLIII] & [Se restituye el epigrafe] \\
\hline 44 & 270v. 5 & Eso no hartis vosotros & Esto no haréis vosotros \\
\hline
\end{tabular}




\begin{tabular}{|c|c|c|c|}
\hline Cap. & Fol.flin. & "Princeps" y Barcelona 1704 & Segunde Madrid y posteriores \\
\hline 45 & 277 v. 30 & cuyo temor & cuyo tenor \\
\hline 46 & 280r. 10 & inexpugnable castillo a fortaleza & inexpugnable castillo o fortaleza \\
\hline 47 & 287 r. 11 & Braemanes & Bracmanes \\
\hline 48 & 292 r. 13 & y ansí fuera & $y$ aun si fuera \\
\hline 49 & 297 r. 16 & Flexmarte & Felixmarte \\
\hline 50 & $302 v .12$ & ha de atender & ha de entender \\
\hline 51 & 306v. 3 & alguno de sus muchos pretendientes cayesen & alguno de sus muchos pretendientes cayese \\
\hline 52 & $310 \mathrm{v} .29$ & cantaban las dedanías & cantaban las letanias \\
\hline
\end{tabular}

\section{APÉNDICE II}

TABLA DE VARIANTES DEL CAPITULO XX DE LA PRIMERA PARTE

\begin{tabular}{|c|c|c|c|}
\hline Núm. & Fol.Alin. & "Princeps" & Barcelona 1704 \\
\hline 1 & $86 v .5$ & por venir a servir & para servir \\
\hline 2 & 86v. 7 & rasgado & resgado \\
\hline 3 & 87 r. 17 & que no se pueda mover & que no se puede mover \\
\hline 4 & 87 v. 28 & Catón Çonzorino Romano & Catón Conzorino Romano \\
\hline 5 & 88 r. 7 & Lope Ruyz & Lope Reyz \\
\hline 6 & 88 r. 8 & Lope Ruyz & Lope Reyz \\
\hline 7 & 88 r. 21 & prosiguió Sancho & prosiguia Sancho \\
\hline 8 & 88 r. 24 & unos pocos de bigotes & unos de bigotes \\
\hline 9 & 88 r. 29 & afirmar y jurar & a firmar y jurar \\
\hline 10 & $88 v .22$ & sólo diere que dicen & sólo diré que dicen \\
\hline 11 & 89 r. 29 & Tan acabada es como mi madre & Tan acabado es como mi madre \\
\hline 12 & 89v. 8 & Acabe norabuena & Acabemos norabuena \\
\hline 13 & 90 r. 11 & que tanta pesadumbre & que tanto pesadumbre \\
\hline 14 & $90 \mathrm{v} .25$ & habia de llevar de su parte a su señora & había de llevar de su señora \\
\hline 15 & 91r. 12 & Seguiale Sancho & Seguiala Sancho \\
\hline 16 & 91v. 1 & Otros cien pasos serian & Otros cien pasos serán \\
\hline 17 & 92 r. 16 & como vos los habreis visto & como vos los habeis visto \\
\hline
\end{tabular}




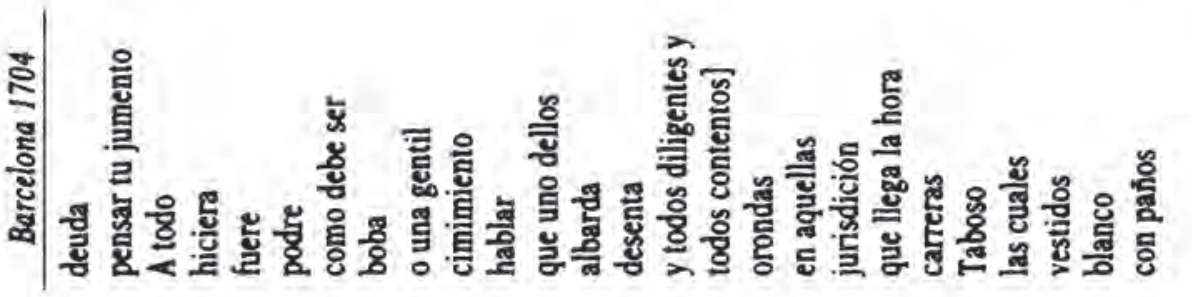

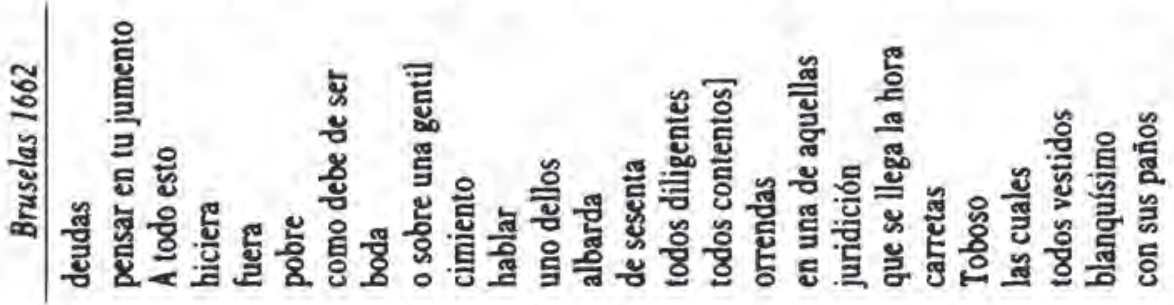

政

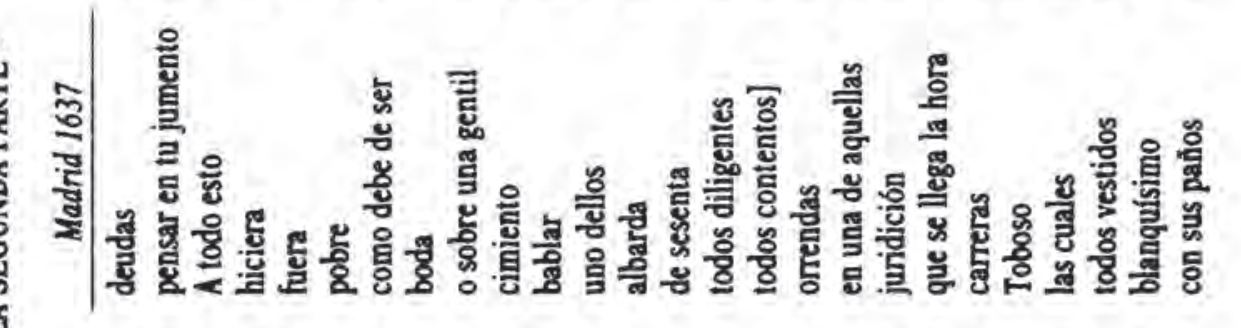

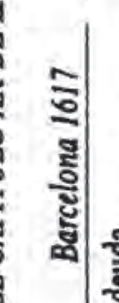

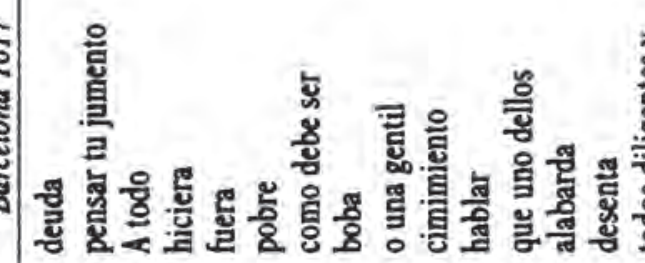

)

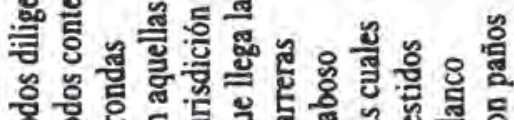

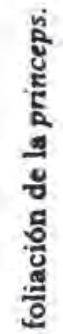

폼

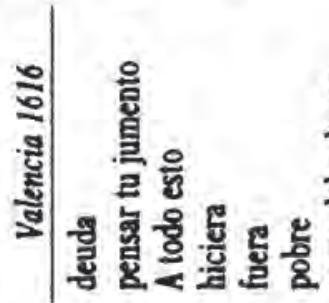

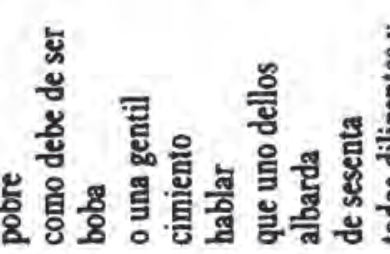

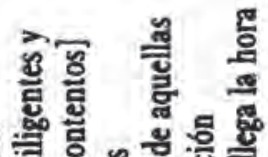

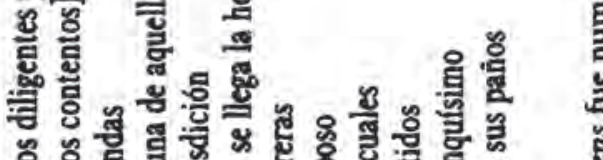

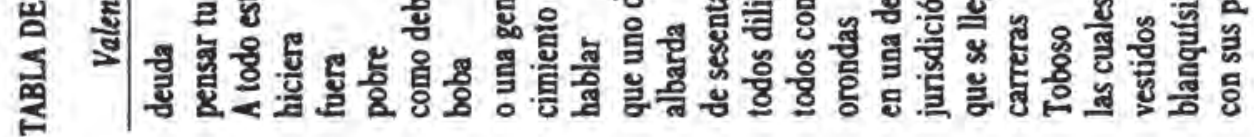

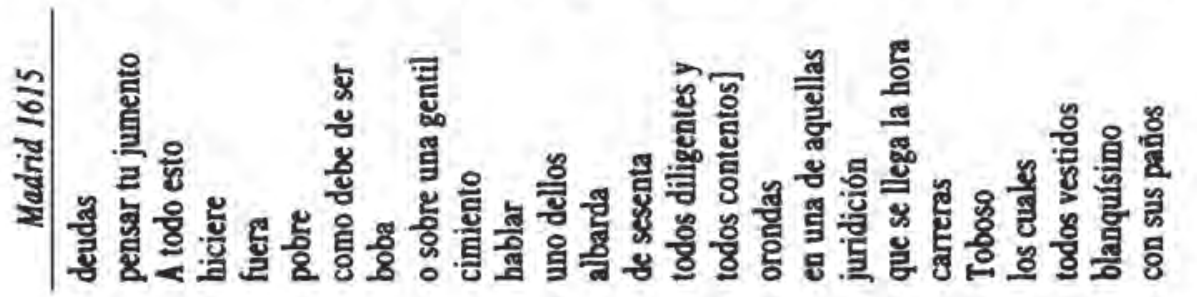

ㄴํㄴ

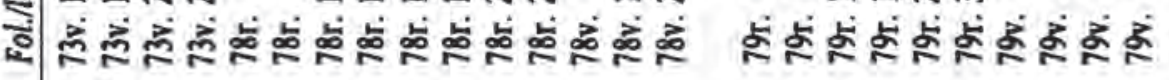

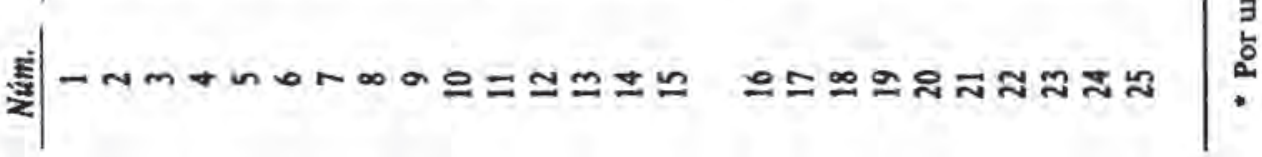




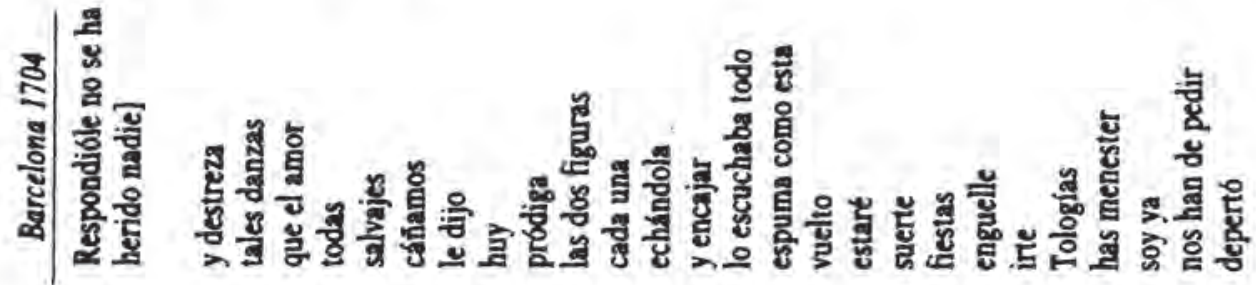

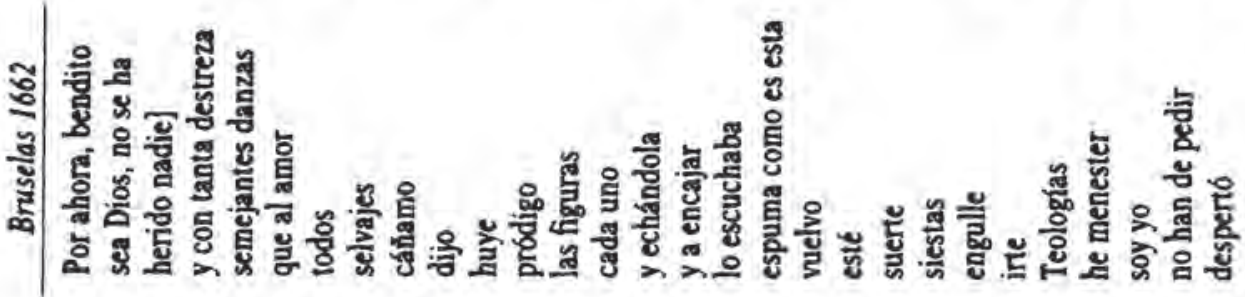

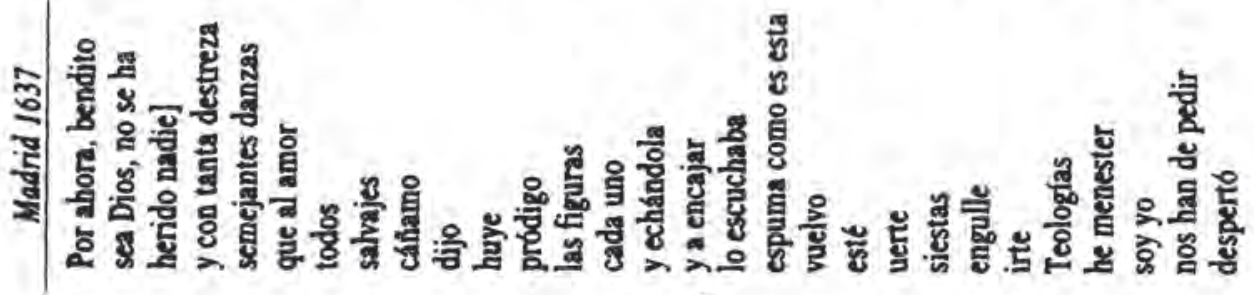
包弯 年

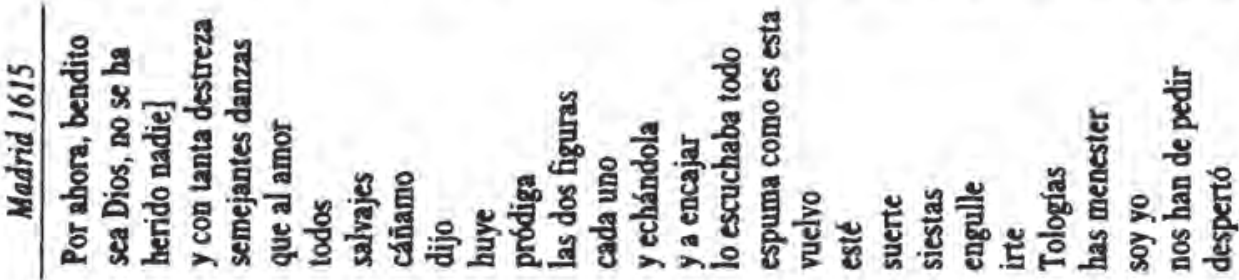

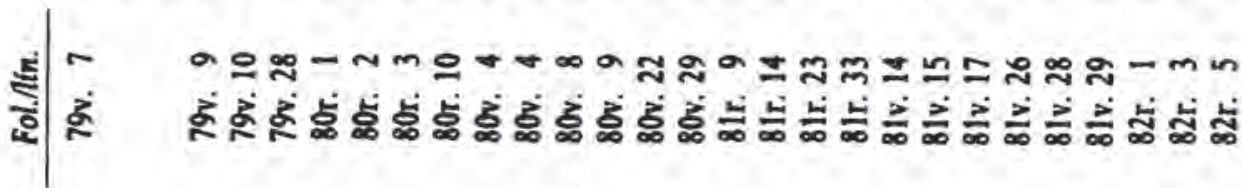
姿| 